\title{
Pier Antonio Borgheggiani, Ordre et Caprice. De Bonstetten à Bourget
}

\section{Rita Sever}

\section{Q OpenEdition}

1 Journals

\section{Edizione digitale}

URL: https://journals.openedition.org/studifrancesi/40856

DOI: $10.4000 /$ studifrancesi.40856

ISSN: 2421-5856

\section{Editore}

Rosenberg \& Sellier

\section{Edizione cartacea}

Data di pubblicazione: 1 juillet 2004

Paginazione: 205

ISSN: 0039-2944

\section{Notizia bibliografica digitale}

Rita Sever, «Pier Antonio Borgheggiani, Ordre et Caprice. De Bonstetten à Bourget», Studi Francesi

[Online], 142 (XLVIII | I) | 2004, online dal 30 novembre 2015, consultato il 09 septembre 2021. URL: http://journals.openedition.org/studifrancesi/40856; DOI: https://doi.org/10.4000/studifrancesi. 40856

Questo documento è stato generato automaticamente il 9 septembre 2021.

\section{(c) (1)}

Studi Francesi è distribuita con Licenza Creative Commons Attribuzione - Non commerciale - Non opere derivate 4.0 Internazionale. 


\title{
Pier Antonio Borgheggiani, Ordre et Caprice. De Bonstetten à Bourget
}

\author{
Rita Sever
}

\section{NOTIZIA}

PIER ANTONIO BORGHEGgIANI, Ordre et Caprice. De Bonstetten à Bourget, Fasano - Paris, Schena

- Presses de l'Université de Paris-Sorbonne, 2002, pp.176.

1 In questa silloge critica l'A. raccoglie otto saggi, pubblicati negli ultimi quindici anni, in volumi non sempre di facile reperibilità, che si focalizzano, o sull'ordine delle idee, come l'ultimo dedicato alla Critique littéraire et critique des idées chez Paul Bourget (pp. 131-165), un'esemplare rassegna dell'introspezione letteraria del discusso romanziere fin de siècle, o sul giudizio arbitrario, ben delineato nelle pagine dedicate a Quelques remarques sur la critique dramatique d'Henri Becque (pp.54-67).

2 Il giudizio di Jules Lemaitre viene rivalutato anche nel saggio successivo, George Sand vue par Jules Lemaitre (pp. 69-86), che analizza il ruolo determinante del critico nell'evidenziare rapporti di contiguità tra il teatro di Alfred de Musset e quello della grande romanziera. Lemaitre propone un'indagine comparative tra le commedie Marquis de Villemer della Sand e On ne badine pas avec l'amour di Musset, per soffermarsi soprattutto sulla sorprendente abilità drammatica della scrittrice. Lo stesso Musset, dice Lemaitre, arriverà a saccheggiare i dialoghi del dramma sandiano Une conspiration en 1537 per il suo Lorenzaccio: un omaggio intertestuale all'amica di talento.

3 Tornando al binomio del titolo, si nota che l'ordine regna sovrano, ma questo è evidente fin dal primo saggio che prende in considerazione la figura del nobile letterato svizzero e viaggiatore, Charles-Victor de Bonstetten (1745-1832), molto attento a prendere le distanze per sé e per i suoi concittadini, dalla Rivoluzione Francese. L'ordine dello studioso, la sua pacata acribia fa chiarezza anche nel capriccioso, vulcanico linguaggio del giovane Napoleone Bonaparte, del quale con amorosa pazienza 
l'A. ci restituisce alcuni esempi in Les manuscrits florentins (Ashburnham 1873) du jeune Napoléon (pp.35-54) di fantasiosa grafia e energica brevità. 